\title{
International Business Negotiation Strategies: Cases of Discrimination in Public Procurements
}

\author{
Kęstutis Peleckis ${ }^{\# 1}$, Valentina Peleckienė ${ }^{* 2}$, Kęstutis Peleckis ${ }^{\# 3}$, Edita Leonavičiené ${ }^{\# 4}$ \\ "Faculty of Business Management, Vilnius Gediminas Technical University,
}

Sauletekio al. 11, LT-10223 Vilnius, Lithuania

\begin{abstract}
In the absence of competition, allowing monopolists to discriminate on prices, sales volumes may increase by adopting lower prices for certain groups of consumers who would not otherwise have purchased. If price discrimination is not perfect, it increases consumer welfare - that is, if the price does not correspond to the evaluation of each product by the consumer, then discrimination allows for additional consumers to buy the product at a price, which is lower than the one they would have liked to pay for it. This often results in negative consequences for both consumers and sellers. In this case opportunities for international business are opening, as intervention from other markets can provide additional alternatives to buyers by reducing the negative impact of distorted competition for the balance of negotiating power of negotiators. But there is another problem here in assessing the concentration of market participants, their impact on price discrimination. The aim of the article is to analyze the existing theory and practice of negotiation strategy in a complex way, at different levels of competition, to reveal possibilities to develop and implement these strategies, taking into account the problems of price discrimination. The object of the article is the preparation of negotiation strategies at different levels of competition, taking into account the problems of price discrimination. The article deals with the problem - there are not enough tools in the negotiation theory to help develop negotiation strategies with different levels of competition and price discrimination problems. The paper analyzes the mathematical model of oligopoly. This model explores the feasibility and effectiveness of negotiation strategy preparation in the face of distorted market competition.
\end{abstract}

Keywords - competition, price discrimination, negotiation strategies, distorted market, monopoly, oligopoly.

\section{INTRODUCTION}

The level of market competition and price discrimination in the market affect the balance of the negotiating power of market participants. This often results in negative consequences for both consumers and manufacturers and sellers. These conditions open up opportunities for international business, as the intervention of other market's representatives can provide additional alternatives, thus reducing the negative impact of distorted competition on the balance of negotiating power of negotiators. However, there is another problem in this case when assessing the concentration of market participants and their impact on price discrimination.

The article examines the possibilities of effective negotiation strategy preparation in case of distorted market competition.

The aim of the article is to analyze in a comprehensive way the existing theory and practice of negotiation strategy, with different level of competition, to reveal possibilities for development and implementation of these strategies, taking into account the problems of price discrimination.

The subject of the study is the preparation of negotiation strategies at different levels of competition, taking into account the problems of price discrimination.

The problem of research - there are not enough tools in the negotiation theory to help develop negotiation strategies, with different levels of competition and price discrimination problems.

\section{Price discrimination}

Price discrimination occurs when a company sells two similar products with the same marginal cost of production at different prices (OECD, 2016a). Price discrimination is generally beneficial for the economy, often for the benefit of consumers as it increases the volume of trade and encourages businesses to compete. However, this may also harm consumers when dominant companies organize discrimination in order to exploit their market power or distort competition in consumer markets (OECD, 2016a; Ghosal and Tonin, 2018; Liu et al., 2018; Schlosser, 2017; Kaplow, 2018; Kumar, 2018; Yasui and Haraguchi, 2018; Chen and Tanaka, 2018; Symeonidis, 2018; Uchiyama, 2018; Gámez et al. 2018). Discrimination that can be treated as an ideal price discrimination, which includes strong pricing for each product, that corresponds to each consumer's willingness 
to pay for that product (OECD, 2016a). Ideal price discrimination is traditionally considered a theoretical concept - although it may be a real entity that can be created using large data. In practice, it is already noticeable non-traditional price discrimination or customized pricing. This is pricing based on the individual characteristics of the buyer (not on the basis of group characteristics). Characteristics used for these purposes may not fully describe each user, but will be sufficient to provide a rough description of the user (OECD, 2016a). Characteristics used to determine personal discounts may include estimates of revenue, results, and expected future earnings. Higher-level discrimination involves firm pricing for different product versions (OECD, 2016a). Here, discrimination is indirect because the choice of the version belongs to the user and not to the seller. Twopart tariffs are used because in such schemes the price paid by the consumer is based on the quantity of product purchased. Ultimately, even higher levels of discrimination include the establishment of strong different prices for different consumer groups with different and noticeable (possibly temporary) characteristics. However, the group can also be described as:

- those who buy in a particular area;

- a particular store;

- when purchased in certain circumstances.

In the markets with networking elements which affect groups of early users or buyers, then in these markets may be lower prices than elsewhere (OECD, 2016a). There may be talk of static, dynamic and intermediate price discrimination (OECD, 2016a). Static discrimination occurs when all products are purchased within one period. This includes non-anonymous discrimination against different consumer groups with different noticeable features. It also includes discounts on quantity or tied discounts. Dynamic discrimination involves cross-border discrimination in which the price changes over time. For example, a company can initially set a high price to sell with a higher margin for the most enthusiastic buyers. However, over time, this price may be lowered in order to make additional profitable sales to those who do not appreciate those products. It is also possible to talk about discrimination in behavior - here the price depends on the behavior of the consumer over a certain period (OECD, 2016a). This "behavior" can be the customer's purchase history from the company (for example, if they purchased the goods at a higher price, and therefore revealed their great desire to buy). As an alternative you can have a wide set of actions (or omissions) over time. Finally, there may be intermediate discrimination where discrimination occurs in the allocation of raw material prices to downstream suppliers, not to end users. For example, in most of the intermediate markets, prices are not reached through the seller, which determines the price, but through bilateral negotiations. This can often lead to different sellers with different prices. This difference may be beneficial as there may be discrimination against intermediaries that is not subject to end-user discrimination (OECD, 2016a).

\section{III.CONDITIONS FOR PRICE DISCRIMINATION}

To be able to claim that there has been any price discrimination, there must be three necessary conditions (OECD, 2016a). Firstly, the company will have a lower demand curve. If a company operates in a fully competitive market, it will reach the market price and will not be able to set different prices. Therefore there is a need for a certain element of market power. However, it should not be a significant market power. It should be emphasized that there is no correlation between the degree of price discrimination and the extent of market power. Secondly, if different buyers have paid different prices, the situation may be considered in arbitration (OECD, 2016a). Arbitration occurs when those customers who pay a low price for a product resell the product to customers who would otherwise pay high prices eliminate the ability of the manufacturer to make a higher profit by setting a higher price for any buyer. And thirdly, a company seeking price discrimination must have a way how to get evaluations of consumer, buyer. These evaluations may be based on product characteristics or available information, or may enable the consumer to disclose information about the valuation of the goods (by choosing the quantity or quality of the product, or at a certain time or under certain conditions). If consumers are completely anonymous and have equal purchases, the company will not be able to set different prices (OECD, 2016a).

\section{IV.ADVANTAGES OF PRICE DISCRIMINATION}

The use of the word "discrimination" can lead to the presumption of dishonesty and skepticism about the possible activity of companies using different prices for similar products (OECD, 2016a). However, price discrimination may not be unfair, which may mean that more consumers are served and those with lower incomes are paying lower prices. In many markets, there is a certain degree of price discrimination that is often used by companies with low market power and the use of discrimination often makes markets more competitive (OECD, 2016a). 


\section{THE IMPACT OF PRICE DISCRIMINATION ON THE MONOPOLY}

In the absence of competition, allowing monopolist price discrimination, output sales volumes may increase with lower prices for those consumer groups that would not otherwise have purchased the goods (OECD, 2016a). If price discrimination is not perfect, it increases consumer welfare, that is, if the price does not correspond to the evaluation of each product by the consumer, then discrimination allows additional consumers to buy the product at a price lower than that they would have paid for it. However, while this discrimination may increase the sales volume of the product, it would also increase the price for those consumers who wanted to pay more for the product, and this higher price would exceed the price some of these consumers wanted to pay (OECD, 2016a). For this reason, some consumers would not have bought the product, even though they appreciate it more than new consumers who buy the product at a lower price. As a result, discrimination can also be ineffective as there is insufficient supply on the market for those who value them the most. In addition, price discrimination also leads to the transfer of consumer welfare to the welfare of producers. For example, the profit from trading to those consumers who would in any case buy (surplus or difference between price and willingness to pay) is passed on to the producer (as a profit). This does not necessarily mean that consumer welfare generally diminishes, even if the volume of production increases, additional benefits for other consumers can be created. It is also not necessarily a reduction in overall well-being. However, this can be done if companies are investing in support of Government or maintaining and improving their ability to discriminate (OECD, 2016a) in order to increase the welfare of producers (as well as the transfer of consumer welfare to producers' well-being).

\section{VI.INFLUENCE OF PRICE DISCRIMINATION ON OLIGOPOLY}

Price discrimination can also benefit consumers by increasing competition (OECD, 2016a). Price discrimination can increase business competition. One such case may be illustrated by a classic example of two companies with differentiated products and able to monitor the behavior and position of their customers in the market. If sellers can see where there are consumers on the market and there is the possibility of discrimination, then sellers have the incentive to unilaterally reduce the price, which they would otherwise charge to those who are closer to their competitors in order to compensate for the costs they would experience, if they would have to travel for further purchases from them. They can do it profitably, because they know what's next and can prevent these customers from reselling the product. At the same time, the seller wants prices to be higher for consumers who are closer to them because it is more comfortable to buy from them. However, if the vendor expects his competitor to offer lower prices to their closest customers to keep them, then he can no longer apply such a high price to those consumers (OECD, 2016a). As a result, he has to reduce the price he charges to nearby users to a level that prevents them from traveling further away to their competitors. Because of the possibility of price discrimination, all consumers face lower prices than they would be if there were no discrimination, because each company would always set the same price at a higher level in order to maximize their profits, which she earns from local consumers (OECD, 2016a) ). The ability to discriminate can be considered a classic game of prison dilemma, in which each company individually wants to reduce the price it charges to customers who would not otherwise buy from them (in order to reconquer buyers from their competitors). However, in this way, manufacturers force competitors to lower their price to consumers. This leads to a loss of profit for the entire branch. The main factor in this scenario is that competing companies have different approaches to the consumers for whom they would like to offer a low price (called a weak market share) and consumers for whom they would like to offer higher prices (which is seen as a strong market segment). On the contrary, there may be cases where companies are close to each other and therefore have the same opinion as to how they will set discriminatory prices. In such a case, price discrimination would increase branch profits and reduce consumer welfare (which would not happen unless there was a significant increase in sales) in the same way as when the seller is a monopolist (OECD, 2016a). Other examples of possible price discrimination can increase competition to include markets where companies seek to recover customers who have been disappointed by competitors in previous periods.

\section{EFFECT OF PRICE DIFFERENCE}

When price discrimination increases profits, it can encourage companies to engage in activities that, in many ways, will help them to achieve higher profits (OECD, 2016a). This could stimulate competition by investing in innovation and reducing costs. Innovation can benefit consumers and also lead to positive externalities if they are used by other companies later. In addition to creating incentives for innovation, price discrimination can also be an important incentive for a monopolist to invest in projects with fixed costs. This may also be an unattractive investment if the company expects it will have to set the price at marginal cost, since the cost of the investment will not be included in the price, and therefore the investment will not be efficient enough (OECD, 2016a). Often, monopolists are allowed to set prices that enable them to earn revenue to cover these costs. In 
this case the price structure is the least distorted. It requires higher prices for those customers who are less flexible in terms of demand and lower prices where there is more elastic demand. Therefore, allowing price discrimination can encourage the monopolist to invest in projects with high fixed costs (OECD, 2016a). Profit growth in some cases may be beneficial for consumers, otherwise benefits are not available (OECD, 2016a). For example, while companies can react to the possibility of price discrimination by investing in innovation, they can increase their investment in profitability in order to gain or maintain anti-competitive protection from the Government. In other cases, companies can invest in how to make more effective use of their price discrimination system by gaining excess profits from consumers, for example by investing in more complex individualized pricing systems or preventing arbitrage (OECD, 2016a). Price discrimination can also harm consumers. There are several reasons why competition authorities can investigate price discrimination or practices that facilitate such activity. There are four categories of concerns about price discrimination: exploitation, distortion, exclusion and those based on justice or other policy objectives (OECD, 2016a).

\section{PRICE DISCRIMINATION THAT CAN HARM CONSUMERS: PRICE DISCRIMINATION IS DISTORTED}

In the case of price discrimination, there is an additional risk that price differences will distort competition between buyers and this will undermine the competitive process, leading to higher prices for end users. This potential, which may harm competition in the consumer market, can be regulated as most jurisdictions have rules that can address this risk, even in the absence of rules on price discrimination (OECD, 2016a). Price discrimination is usually common to many economies and is often beneficial to consumers in increasing trade and encouraging companies to compete (OECD, 2016a). First, breakdown strategies that facilitate exploitative price discrimination can increase pricing and increase market power. Such risks are likely will increase, as large data allow companies that are exposed to low competition to be more able to personalize their prices and to obtain a surplus of profits from consumers without expanding production. If evidence shows that this monopolization strategy is detrimental to consumers (taking full account of dynamic incentives to innovate or seek profitability), agencies that regulate competitiveness should seek out cases where priorities are equally important (OECD, 2016a). Where there is no specific division strategy, price discrimination can be more harmful to consumers. This shows that those cases of price discrimination that do not aim at maximizing strategic profit should not be a priority (OECD, 2016a). Under certain circumstances, price discrimination between intermediaries can distort competition and harm consumers. When investigating such consequences, price competition agencies should focus on the likely impact on consumers rather than on whether competitors are harmed (OECD, 2016a). The proposal's counterfeit (or secretly agreed offer) occurs when companies are expected to compete, but they secretly agree to increase prices or deteriorate quality of goods or services, which buyers want to buy by tender (OECD, 2014). Public and private organizations often rely on competitive tendering to get better value for their money. Low prices and / or better products are more desirable because they either result in savings or release them for the purchase of other goods and services. Competitively, lower prices or better quality and innovation can only be achieved if companies really compete (offer their prices and conditions fairly and independently). Counterfeit offers can be particularly harmful if they affect public procurement. Such chats absorb the funds of buyers and taxpayers, undermine public confidence in the competitive process and undermine the benefits of competitive trading (OECD, 2014). Secret agreements on counterfeiting can take many forms, all of which make it difficult for purchasers, often state and municipal, to buy goods and services at the lowest possible cost (OECD, 2014). Often, competitors will agree in advance on who will provide the best (winning) proposal for the contract to be awarded through a tender. The overall purpose of secret agreements is to increase the scope of the winning bid, and thus the volume that the winning offer will receive. The counterfeiting of bids is often designed to distribute the additional profit that the liars have to agree on the final higher price. For example, competitors who agree not to take part in a tender or to submit a losing bid may receive subcontracts or supply contracts from the successful tenderer, thereby sharing the unlawful proceeds for a higher bid. However, for a long time, bidding offers appear more and more ways to select the winner, control and distribute the benefits of counterfeit bids more than a month or a year. It may also be a secret agreement that the winner will be paid in cash to one or more participants in the agreement. This socalled compensation is related to companies that offer "shelter" (more expensive) offers. While individuals and businesses can agree to implement a variety of ways to counterfeit offers, they usually implement one or more common strategies. These techniques are not mutually exclusive. For example, a "shelter" offer can be used in conjunction with the bid rotation principle. In turn, such techniques may be recognized by the organizers of the competition, who may subsequently help to reveal such forms of counterfeiting (OECD, 2014).

"Shelters" (also known as add-on, courtesy, or symbolic) is the most common way to counterfeit the offer. It is when individuals or businesses agree to submit bids that contain one of the following:

- the competitor agrees to offer a higher price than the winner selected,

- a competitor offers a price, knowing that it will be too high and therefore unacceptable, 
- the competitor offers some special conditions, knowing that they will be unacceptable to the buyer.

"Shelters" offers are used to create a real competition image. Blocking a proposal is an agreement between competitors where one or more companies agree not to participate in the competition or to withdraw already submitted tenders in order to accept the successful tenderer's offer. In principle, blocking a proposal means that the company does not submit a proposal for final reading. In the case of a proposal rotation, secret companies provide deals, but agree to win the competition (i.e. offer the lowest price) alternately. The ways in which the proposal rotates may vary. For example, speakers can choose to give each company roughly the same monetary value for each particular contract group or allocate quantities that correspond to the size of each business. Competitors unlawfully share the market and agree not to compete for certain buyers or in certain geographic areas. Competing companies, for example, can distribute certain buyers or groups of buyers to different companies in such a way that competitors do not make bids (or offer "shelter" offers) for contracts offered by certain groups of potential buyers already assigned to a particular company. The competitor will then not offer a competitive offer to a particular group of customers already contracted to another company (OECD, 2014). Although bids can be counterfeit in any industry, there are a few branches where counterfeit offers are more likely due to small amount of companies which supply products or services. These features make it easier for companies to make fraudulent offers. Signs of falsification of proposals may be more significant when there are certain contributing factors. In such cases, the purchasing agents must be particularly vigilant. While various industry or product features may facilitate the secret agreement, but not all of them (features) are needed to be for successful agreement. In order successfully implement their secret agreements, companies need to agree on common arrangements for implementing the agreement, to control if other companies are in agreement, and to find a way to punish fraudulent companies (OECD, 2014). It is more likely that the offer will be counterfeited when few companies are supplying goods or services. The fewer the sellers, the easier it is for them to agree on how to falsify their bids. Few companies enter the market or not at all. When only a few companies have recently entered the market or are expected to enter, as it is expensive, difficult or slow, companies already in that market are protected from competitive pressure from the newcomers. Protective barriers facilitate the falsification of the proposal (OECD, 2014). Significant changes in demand or supply conditions on the market may have an impact on the destabilization of the ongoing agreement and on counterfeiting of the proposal. The steady, predictable demand for public sector demand tends to reinforce the risk of conversation. However, in the event of economic turmoil, crisis or uncertainty, competitors' incentives for secret secretion are increasing as they seek to compensate for the loss of business that is likely to result in business losses (OECD, 2014).

Industry associations can be organizations promoting the competitiveness of the business, the business or the service sector, focusing on standards, innovation and the development of competition. Conversely, when pursuing unlawful anti-competitive objectives, these associations can be used by business representatives for meetings and secret discussions by providing ways and means of concluding and implementing agreements on counterfeiting of offers (OECD, 2014).

Repeated purchases increase the likelihood of plot. Frequency of tenders helps the members of a secret agreement to contract among themselves. In addition, the members of the cartel can punish the fraudster by targeting offers that have already been assigned to it. Thus, in the case of permanent and recurring service or commodity contracts, special measures and vigilance are required to break down the secret offers. When individuals or businesses sell identical or very similar products or services, it is easier for companies to agree on a common price structure. When there are just a few good alternative products or services that can replace the products or services you buy, people or businesses who want to make fraudulent offers are more secure knowing that the buyer has just a few good alternatives, then their efforts to increase the price are more likely will be successful (OECD, 2014). Innovations in small or non-existent goods or services help companies agree and maintain such an agreement for some time.

Information collection about products and / or services on the market that meet the buyer's requirements, as well as information about potential suppliers of these products, is the best way for sales representatives to plan a tender and get the best "value for money". Expertise "at home" should be done as early as possible (OECD, 2014). This requires to look at the nature of the market in which the products or services are to be purchased and what may affect competition during the tender. It is necessary to determine whether the market in which the products or services are to be purchased have features that would make the relationship more likely (OECD, 2014). It is necessary to collect information on potential suppliers, their products, their prices and their costs. If possible, it should be compared to the prices offered at the time of special purchase. It is appropriate to collect information on recent price changes, to analyze prices in neighboring countries and to find out the prices of possible alternative products. It is necessary to collect information about tenders for the same or similar products. It would be useful to contact other public sector buyers and customers who have recently purchased similar products or services to better understand the market and its participants. When hiring consultants to help you calculate prices or costs, you need to make sure that they have signed a confidentiality agreement (OECD, 2014). 
The effectiveness of competition can be enhanced if a sufficient number of reliable predecessors can respond to the invitation to tender and have an incentive to compete for the proposed contract. For example, participation in a tender can be simplified if the purchasing agents reduce the cost of the offer, impose requirements for participation that are unreasonably restrictive of competition, allow companies from other regions or countries to participate, or come up with ways to encourage small businesses, even if they cannot win at all (OECD, 2014). Unnecessary obstacles should be eliminated, reducing the number of qualified candidates. It is appropriate to specify minimum requirements that should be proportionate to the size and content of the contract (OECD, 2014). The requirement for tenderers to secure large monetary guarantees as a condition of participation in a competition may prevent qualified small applicants from participating in the competition (OECD, 2014). Where possible, restrictions on foreign participants should be reduced. As far as possible, it is appropriate to select applicants during the competition to avoid pre-selection interviews and to increase the uncertainty between the number and identity of the applicants. Efforts should be made to reduce the cost of preparing the proposal. This can be done in several ways:

- simplifying tender procedures (using the same application forms, same information, etc.);

- grouping of tenders (different procurement projects), thus allocating fixed costs of tender preparation;

- protecting the official list of approved participants or a certificate from an official certification body;

- giving companies enough time to prepare and submit proposals. For example, considering the possibility of publishing information on a new project well in advance through trade and professional newspapers, websites or magazines;

- if possible, using the electronic submission method.

Wherever possible, it is appropriate to allow bids for a particular batch or object that is part of the contract, or for their combinations, rather than focusing solely on the whole contract. For example, in the larger contracts proposed, it is appropriate to look for parts that are attractive and acceptable to small and medium-sized businesses. Candidates from further bidding should not be disqualified or immediately removed from the list if they have failed to submit a bid in a recent competition. Flexibility is needed for companies that are waiting for offers. For example, if bids from 5 companies are expected, but only 3 bids are received, it is appropriate to consider whether it is possible to get the right offer from those 3 companies rather than to require a reorganization of the competition, indicating that there is a lack of competition (OECD, 2014).

The preparation of requirements and conditions (hereinafter referred to as "RC") is one of the phases of the public tender that is not protected from tendency deviations, fraud and corruption (OECD, 2014). The RC must be designed in such a way as to avoid tendency deviations, be clear and comprehensive, but not discriminatory. They need to be focused on functional characteristics, that is, what is being done, with less attention being given to how this is to be done. This would encourage new solutions. The number of suppliers to be attracted and, ultimately, the success of the selection process depend on how the terms of the competitive tender are written. The clearer the requirements, the easier it will be for potential suppliers to understand them and to be more selfconfident when preparing proposals. Clarity should not be confused with predictability. The more predictable purchase schedule and the unchanged quantities sold or purchased make it possible to negotiate secretly. On the other hand, higher value and less frequent procurement tenders increase the incentives for competitors to compete. The requirements of the competitive tender should be as clear as possible. Conditions must be independently verified before they are finalized to ensure that they are clearly understood. Efforts should be made not to leave the winner of the competition free to set the basic conditions (OECD, 2014). The performance specifications should be used and point out what is actually required but not to give a product description. It is not appropriate to publish a tender until the contract is still in the initial stage of the description of the characteristics: a detailed description of the needs is the key to good purchasing. In rare cases, when this cannot be avoided it is possible to ask applicants to offer a unit price. This price may subsequently be adapted, adjusted for quantities of goods (OECD, 2014). Wherever possible, characteristics that allow product substitutability or functional characteristics and conditions should be defined. Alternative or innovative sources of supply make it difficult adoption of collusive conduct. Predictability of contractual conditions should be avoided: mergers or divisions of contracts can be considered, options for changing the scope and deadlines of applications can be analyzed. Opportunities should be sought to work with other public sector purchasers and co-operate with procurement (OECD, 2014).

When planning procurement tenders, the organizers of the procurement should have analyzed various factors that can facilitate conversation. The efficiency of the procurement process depends on the chosen model of the tender as well as on how the tender will be organized and executed. The correct procurement procedure requires transparency requirements to help fight corruption. Transparency requirements must be strictly adhered to in order not to create opportunities for competitors (tenderers) to enter into conversations. Unfortunately, there is no single "golden" rule for planning an auction or buying a tender. The competition must be organized in a way that is appropriate to the circumstances. Interested suppliers can be invited to talk to the contracting authority 
about the technical and administrative conditions of the purchasing options. However, the participation of potential suppliers in the organization of such meetings should be avoided. As far as possible, applicants' communication during the competition should be limited. Open competitions allow applicants to communicate. The requirement that a tender be submitted in person gives the representatives of the companies applying for the competition the opportunity to interact last minute and negotiate. This can be avoided, for example, by using the electronic submission method. It is advisable to consider carefully what information is disclosed to applicants at the time of the public offer. Publication of the tender results requires careful consideration of what information is published, and it is necessary to avoid disclosing competitively sensitive information as this may later lead to fraudulent bidding schemes. When it is possible to suspect a possible plot, an auction should be used when the first bid is placed in a sealed envelope. Consideration should also be given to whether a different type of procurement than a one-tier tender, in particular an unbreakable price, would produce a better result. Where possible, it should be provided that tenders are submitted anonymously (identification numbers and markers are provided to tenderers) by making offers by telephone or e-mail. Cannot disclose or limit unnecessarily the number of candidates. It is necessary to provide that applicants must disclose all links with their competitors. It is appropriate to require applicants to disclose in advance whether they will use the services of subcontractors this could serve to distribute profits among speakers. Since joint offers can be a way of sharing profits between speakers, one must be particularly vigilant about the joint proposals of such companies. It should be known whether these companies have already been penalized by the competition authorities for their conversations. Caution should be exercised even if the conversation has been in other markets or if these companies have no capacity to make separate independent offers (OECD, 2014). The tender proposal should include an alert for sanctions in your country for falsification of the offer, that is suspension for a certain period of time in public procurement. If the participants in the conversation have signed the Confirmation of the Independent Proposal, they must be informed that the purchasing organization has the possibility to seek redress and other sanctions under the Competition Act. Applicants must be informed that any statement of cost increases that will lead to an increase in the budget will be thoroughly examined. If you use the services of external consultants during the procurement process, you need to make sure that they are properly trained, that they have signed a confidentiality agreement and that they comply with the requirement to report known unfair competition behavior or any potential conflict of interest (OECD, 2014).

The above mentioned criteria affect the intensity of competition and the effectiveness of competitions. The decision on which criteria to choose and use for the planned public tender is very important. This is also relevant for the preservation of potential reliable applicants, in the hope that they will be interested in future projects. It is therefore important to ensure that qualitative selection and decision-making criteria are selected in such a way that reliable applicants, including small and medium-sized enterprises, are not unduly discouraged (OECD, 2014). When planning a competitive bid, it is necessary to consider how the optional criteria will affect future competition. When pre-candidates are judged by a different criterion than the price (product quality, after-sales service, etc.), these criteria must be sufficiently described and considered in advance to avoid misunderstandings, sometimes resulting from the winner's announcement. To what extent is the scale of disclosure of the Critical criteria may, before the end of the competition, affect the ability of applicants to match the joint proposal (OECD , 2014). Any prior assessment of a particular supplier or group of suppliers should be avoided. Cannot be supported current vendors. Measures that maximize anonymity during the purchasing process can counteract the benefits of the current supplier. Whenever possible, it is appropriate to consider other appropriate experience. Surveys should be conducted if prices or offers are incomprehensible, but never can these issues be discussed with all tenderers. As far as possible, the pricing and terms of each firm's bid must be kept secret in accordance with the legal requirements governing the winner's announcement. The participants in the contract preparation process should be instructed on strict adherence to confidentiality (OECD, 2014). It is appropriate to reserve the right not to award the contract if there is a suspicion that the tender is not competitive.

Appropriate training is important to enhance the understanding of competition concerns by procurement agents during public procurement. Efforts to combat counterfeiting effectively can be reinforced by gathering historical information on bidders' behavior during bidding, by constantly monitoring bidding and analyzing bids. This helps procurement authorities (and competition authorities) to identify problem situations. It should be noted that the results of one tender may not clearly show that the offer was counterfeit. Often, talk plans are revealed only after analyzing the results of several competitions that have been conducted for a certain time (OECD, 2014). Together with the competition authority or external legal experts, it is appropriate to implement training for their employees on counterfeiting and disclosure of cartels (OECD, 2014). Information on past competitions (information on purchased products, proposals from each participant, winners' identities, etc.) must be retained. The history of tenders for individual products or services should be reviewed periodically and try to identify suspicious examples, especially in those susceptible sectors. It is appropriate to list the companies that have expressed interest in the tender and the companies that have submitted the tenders in order to assess 
possible trends, tendencies of withdrawal of tenders and use of contractors were determined. It is advisable to talk to sellers who are no longer involved in competitions and unsuccessful sellers. There should be a mechanism in place for the companies involved in the competition to report any potential competition breaches. For example, the person or department to be notified (with their contact details) should be clearly identified, ensuring an appropriate level of confidentiality. It would be useful to use tools such as a "scooter" system, information about secret agreements is obtained from companies and their employees, and so on. Sometimes it would be advisable to use the media to invite companies to provide information about possible interactions with interested authorities (OECD, 2014). It is necessary to have a good knowledge of the current system of leniency in the country, if any, and to review its policy of refusing entry. If there is evidence of signs and actions of plot, in order to determine whether it is consistent with your country's system of fines. It is advisable to establish internal procedures that encourage or require purchasing agents to notify not only the procurement body's internal audit team and the controller, but also the competition authority of suspicious features and actions, and to provide incentives to encourage purchasing agents to do so (OECD, 2014). Provision should be made for cooperation with competition authorities by establishing appropriate forms of cooperation, information to be provided to competition authorities and so on. It may be very difficult to trace agreements on counterfeiting, as they are usually negotiated secretly. In industries where plots are common, suppliers and purchasers may have knowledge of old secret agreements on counterfeiting. In most cases, it is necessary to look for evidence such as a regular bid or price structure, or something that the salesperson said or did. It is necessary to be vigilant in all tenders for purchase or sale as well as in the preliminary market research (OECD, 2014).

It should be noted that certain models and actions of the proposals appear to be inconsistent with the competitive market and suggest the possibilities for counterfeiting the proposals. It is needed try to look for unusual bidding models and watch how often they win or lose competitions. The involvement of contractors and actions by unions of joint ventures may also raise suspicion (OECD, 2014). Here are some examples: for example, the same supplier often offers the lowest price, or there is a geographical distribution of tenders. Some companies offer bids only in certain geographic areas. A permanent supplier does not provide for the tender, from which it is usually expected that he will submit a tender but puts forward proposals for other competitions. Some suppliers unexpectedly withdraw their offers. Some companies always make offers, but never do it. There may be a tendency for a company to submit a winning bid from a set of potentially mutually exclusive queues. Two or more companies submit a joint offer, although at least one of them could make a separate offer. The winning bidder repeatedly provides the contract to the losing company. The winner does not sign the contract, and then it turns out that he is a subcontractor. Competitors often communicate or arrange meetings just before the closing date of the competition.

Signs of collusion on bidding for bidding can be found in various documents provided by companies. While the companies involved in the collusive agreement will try to keep the secret agreement in secret, the negligence, frustration or guilt of some participants may help to uncover the secret deal. By carefully comparing all the documents, it is often possible to ascertain whether the proposal was prepared by the same person or prepared together (OECD, 2014). There may be similar mistakes in the offer document or in letters from different companies, such as spelling errors. Offers from different companies may contain similar records, handwritten or similar, or use the same forms. One company offer documents may contain a clear reference to a competitor's offer to use another applicant's letter or fax number. The bids in the different companies have the same calculation errors. There are a number of uniform estimates of prices for certain goods in the offers of different companies. Different business packages are marked with similar postage stamps or postage stamps. There are quite a few last-minute fixes, such as the use of trimmers or other physical changes, in the offer documents of different companies. The tender documents submitted by different companies contain fewer details than would be necessary or likely to be, or else it can be understood that $\mathrm{s}$ is a false offer. Competitors make similar suggestions, or the proposed price increases with regular growth.

Bid price analysis can help to reveal collusion. This requires looking for examples that show that companies can coordinate their actions, such as price increases, which are unlikely to result in cost increases. When losing bids are much more expensive than the winner's bid, spokespeople can use the "shelter" bidding model. The usual practice of using such offers is when the bidder's adds $10 \%$ or more to the lowest bid. Higher bid prices than estimated design costs or higher than previous bidding tenders can also lead to suspect talk. This can be a sudden and uniform increase in bidders' prices or price ranges, which cannot be explained by an increase in costs. Expected discounts are suddenly disappearing. Equal prices can lead to particular suspicions when one of these conditions exists (OECD, 2014):

- supplier prices have been the same for a long time;

- the prices of different suppliers were different before;

- suppliers have increased prices and this is not due to cost increases or

- suppliers have abandoned discounts in markets where discounts have always been. 
Attention should be paid to the large price difference between the winner and other offers. The offer of a particular supplier is much more expensive for a particular contract compared to the same supplier's offers for other similar contracts. It may be that the offer to a new or rarely tendered supplier has resulted in a significant reduction in price compared to the former price level, which means that the new supplier could have ruined the existing cartel. There are cases where local suppliers offer higher prices for local deliveries than for future deliveries. It is possible that local and non-local companies indicate similar transport costs. Attention should be drawn to the case where only one tenderer contacts the wholesaler for price information before submitting bids. There may be some signs of unexpected public offers being made at auctions, by electronic or other means, such as suggestions for unusual numbers when the number can be expected to be rounded up to one hundred or one thousand, with such features suggesting that bidders use the same suggestions as a conversation by exchanging information or signaling priority (OECD, 2014). When dealing with sellers, you should always look carefully at suspicious statements that might indicate that companies have agreed or coordinated their actions or sales actions (OECD, 2014). There may be hints orally or in writing about the applicant's agreement. Claims that bidders justify their prices at "industry-quoted prices", "standard market prices" or "industry pricing", etc. are suspicious statements, suggesting that certain companies do not sell in certain territories or sell to certain customers. It should be noted that the territory or the buyer is "owned" by another supplier. Some statements may indicate that prior information about the competitor's prices or details of the offer is known in advance, or knowledge of the company's winning or defeat in a tender whose results will only be published. Attention should be drawn to the statements that the supplier has submitted a courtesy, complementary, symbolic, recognizable or "shield" offer. Suspicious can be, when different suppliers use the same terminology to explain the reason for the price increase. It may be suspicious if questions are raised or concerns about the approval of the Independent Proposal setting or a reference to the fact that it is signed (or not even signed), but not seriously evaluated. Attention should be drawn to the letters of the tenderers refusing to comply with certain conditions of the tender or the various discussions, for example, possibly with trade associations.

Attention should be drawn to hints about meetings or events where suppliers could discuss prices or conduct behavior in relation to a particular tender. These clues may indicate that one or another company is taking some action that is beneficial to other companies. Suspicious behavior may occur when (OECD, 2014):

- suppliers meet privately before submitting their bids, sometimes close to where the bids will be made;

- suppliers are in regular communication or meetings;

- the company or its representative asks for a package of offers for himself and his competitor;

- the company submits its own and competitor's offers and other documents;

- the proposal is submitted by an undertaking that does not have the potential to perform the contract;

- the company has several suggestions and is considering which offer to submit when it learns (or tries) find out who still makes the offers;

- several bidders ask similar questions or make similar requests or documents to the buyer.

Possible signs of counterfeiting of the offer described above identify many suspicious offers and pricing methods as well as suspicious statements and behavior. However, it should be borne in mind that this is not evidence that companies are making fraudulent offers. For example, the company does not participate in the competition because its employees were just too busy at the time. Expensive offers can simply point to the use of different methods of calculating project prices. However, when it comes to specifying suspicious bidding patterns and prices, or when buying agents hear strange claims or behave in a particular way, a counterfeit investigation is needed. Constant examples of suspicious behavior over a period of time are often a better sign of the potential offer counterfeiting than the evidence from a single offer. By carefully collecting the entire information history, case of this behavior can be identified (OECD, 2014).

If there is a suspicion that a fraudulent offer is being made, there are many ways to disclose this and stop it. First of all, you need to be familiar with the rules of your jurisdiction regarding counterfeiting offers. Under no circumstances should you discuss your insights with suspicious contestants. It is necessary to keep all documents: tender documents, correspondence, envelopes, etc. You need to keep detailed records with dates of all suspicious behavior and formulated statements, paying attention to who was involved, and what exactly happened or was told. Records must be made during or immediately after the event to clearly and comprehensively describe what has emerged and become apparent. If necessary, you can contact your national competition authority. After consulting your lawyers, you have to decide whether you can continue the competition (OECD, 2014).

\section{IX.THE NEED TO CONSIDER OLIGOPOLIES IN THE PREPARATION OF BUSINESS NEGOTIATION STRATEGIES}

Oligopoly is a case of market relations where the number of sellers or service providers is not sufficient for fair competition. Because there are few sellers, the decisions of each of them have an impact on the remaining sellers. Strategic planning of activities in the context of oligopoly, including the development of international 
business negotiation strategies, must always take into account the expected reaction and response of other oligopolists.

Mathematically, oligopoly is usually defined by the so-called ratio of four firms concentration. If the four largest firms in the economy control more than 40 percent of production, this sector is considered to be an oligopoly. For example, in UK the four largest supermarket chains control 70 percent of sales - it is an oligopoly.

Oligopoly is a distortion of competition, for which the laws of the free market are incomplete, only specific. In addition to the usual methods of fighting the market, oligopolists often play against each other, not by reducing sales prices, but using a variety of other methods that are less common in a market economy: the manufacturer's "tying" (discount cards and other sophisticated loyal customer-friendly sales schemes), very active advertising and the development of new products and services (the latter is a useful form of fighting for the consumer). Entrance barrier under oligopoly conditions is usually high. Below we will describe the oligopoly model.

Products / services are produced / provided by $\mathrm{n}$ business entities. Cost of a i business entity in the production of ki units: Di (ki ), where Di there is no negative and growing. If the total output of business entity is Z, then the market price will be $\mathrm{X}(\mathrm{Z})$, when $\mathrm{X}$ does not increase.

Business entity's i full production profit function is:

$$
\pi_{i}\left(k_{i}, \ldots, k_{n}\right)=k_{i} X\left(\sum_{j=1}^{n} k_{i}\right)-D_{i}\left(k_{i}\right)
$$

Two business entities are involved. Reverse demand:

$$
X(Z)=\max \{0, \propto-Z\}=\left\{\begin{array}{c}
\alpha-Z \text { jei } Z \leq \alpha \\
0 \text { jei } Z>\alpha
\end{array}\right.
$$

Constant unit price:

$$
D_{i}\left(k_{i}\right)=c k_{i} \quad \text { where } \mathrm{c}<\alpha,
$$

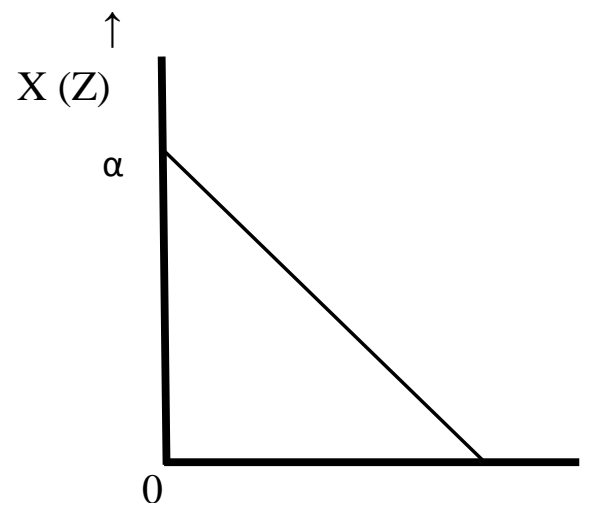

Fig. 1. Oligopoly model

Under the conditions of an oligopoly, there is always a risk that all oligopolists will agree with each other and at the same time will set higher market prices when forming a cartel. The law of the monopoly is already in force for the cartel. In most countries, cartel formation is illegal.

\section{Conclusions}

1. In the absence of competition where a monopolist is able to apply price discrimination, sales volumes may increase when a monopolist fixes lower prices for groups of consumers who would not have bought at higher prices. If price discrimination is not perfect, then this discrimination increases consumer welfare, that is, if the price does not correspond to the evaluation of each product by the consumer, then discrimination allows additional consumers to buy the product at a price lower than that, which they would have paid for it. However, while this discrimination may increase the sales volume of the product, it would also increase the price for those consumers who wanted and could pay more for the product, and this higher price may exceed the price that some buyers from this consumer group expected to pay. For this reason, some customers from this consumer 
group will not buy the product, even though they value it more than new consumers who buy the product at a lower price. In such a case, discrimination can be ineffective because the market does not offer enough products or services at a reasonable price to those who value them most. In addition, price discrimination also leads to the transfer of consumer welfare to the welfare of producers. For example, the gain from trading with those consumers who would buy in any case (excess or difference between price and willingness to pay is passed on to the producer (as a profit). This does not necessarily mean that the total consumer welfare is reduced, because if the volume of the production sales increases, it can be created additional benefits for other users.

2. Price discrimination can also be a benefit to consumers in increasing competition. Price discrimination can increase business competition. One of such cases may be illustrated by a classic example of two firms with differentiated products, which are able to monitor the behavior of their customers. If sellers can see that they are able to discriminate their consumers, then sellers have the incentive to reduce the price unilaterally, which they would otherwise only apply to those who are closer to their competitors in order to compensate those consumers for the necessity to travel further to purchase goods from them. Manufacturers can do this in a profitable way, because they know what their customers are, and can apply prices that prevent these customers from reselling their products. The seller wants prices to be higher for those users who are closer to him, so that they would be more comfortable buying from them. However, if the seller predicts that his competitor will offer lower prices to his closest customers to maintain them, then the seller will have to apply less competitive prices to those consumers in order to maintain them.

3. In the face of price discrimination, there is an additional risk that the price difference will distort competition and this will undermine the competitive process leading to higher prices for end users. This potential, which could harm competition in the consumer market, means that most jurisdictions have rules that address these risks, even in the absence of rules on the use of price discrimination. Price discrimination is often beneficial for consumers by expanding trade and encouraging companies to compete.

\section{REFERENCES}

[1] Chen, Y.; Tanaka, M. 2018. Permit banking in emission trading: Competition, arbitrage and linkage, Energy Economics, Volume 71, Pages 70-82, ISSN 0140-9883, https://doi.org/10.1016/j.eneco.2018.01.032

[2] Gámez, M.; López, I.; Rodríguez, C.; Varga, Z.; Garay, J. 2018. Game-theoretical model for marketing cooperative in fisheries, Applied Mathematics and Computation, Volume 329, 15 July 2018, Pages 325-338, ISSN 0096-3003, https://doi.org/10.1016/j.amc.2018.02.017.

[3] Ghosal, S.; Tonin, S. 2018. Noncooperative Oligopoly in Economies with Infinitely Many Commodities and Traders, Games and Economic Behavior, ISSN 0899-8256, https://doi.org/10.1016/j.geb.2017.12.015

[4] Kaplow, L. 2018. Price-Fixing Policy, International Journal of Industrial Organization, ISSN 0167-7187, https://doi.org/10.1016/j.ijindorg.2017.12.008.

[5] Kumar, P. 2018. Market Power and Cost Efficiencies in Banking, International Journal of Industrial Organization, ISSN 0167-7187, https://doi.org/10.1016/j.ijindorg.2018.02.003.

[6] Liu, Q.; Wang, L. F. S.; Chen, C. L. 2018. CSR in an oligopoly with foreign competition: Policy and welfare implications, Economic Modelling, ISSN 0264-9993, https://doi.org/10.1016/j.econmod.2018.01.002.

[7] Madeikytė, N. 2011. Tiesiniai modeliai Nešo pusiausvyrai rasti. 14-osios Lietuvos jaunujų mokslininkų konferencijos „,Mokslas Lietuvos ateitis“, 1-4 p. ISSN 2029-7149 online 2011 metų teminès konferencijos straipsnių rinkinys ISBN 978-9955-28-836-7.

[8] OECD. 2004. Factsheet on how competition policy affects macro-economic outcomes. $34 \mathrm{p}$.

[9] OECD. 2012. Market definition. DAF/COMP(2012)19. 441 p.

[10] OECD. 2014. Recommendations for combating bid falsification in public procurement. $15 \mathrm{p}$.

[11] OECD. 2015. Competition enforcement in oligopolistic markets. DAF/COMP. 9 p.

[12] OECD. 2016a. Competition assessment toolkit. Principles. Vol. 1. 46 p.

[13] OECD. 2016b. Defining geographic markets across national borders. DAF/COMP/WP3(2016)5. 27 p.

[14] Schlosser, R. 2017. Stochastic dynamic pricing and adve tising in isoelastic oligopoly models, European Journal of Operational Research, Volume 259, Issue 3, Pages 1144-1155, ISSN 0377-2217, https://doi.org/10.1016/j.ejor.2016.11.021.

[15] Symeonidis, G. 2018. Collusion, profitability and welfare: Theory and evidence, Journal of Economic Behavior \& Organization, Volume 145, Pages 530-545, ISSN 0167-2681, https://doi.org/10.1016/j.jebo.2017.11.010.

[16] Uchiyama, T. 2018. Quasi-competitiveness in the Cournot model with heterogeneous firms, Economics Letters, Volume 165, Pages 62-64, ISSN 0165-1765, https://doi.org/10.1016/j.econlet.2018.02.006.

[17] Yasui, Y.; Haraguchi, J. 2018. Supply function equilibria and nonprofit-maximizing objectives, Economics Letters, Volume 166, Pages 50-55, ISSN 0165-1765, https://doi.org/10.1016/j.econlet.2018.02.008. 